\title{
DOENÇAS E AGRAVOS PREVALENTES EM CRIANÇAS DE UMA CRECHE PÚBLICA: O OLHAR DOS FUNCIONÁRIOS DA CRECHE
}

\author{
Diseases and prevalent diseases in day care children: the look of the nursery staff \\ Las enfermedades y las enfermedades de alta prevalencia en niños de guardería: el \\ aspecto del personal de enfermeira
}

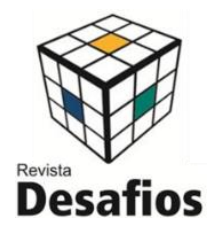

Sandra Trindade Low*1, Amanda Katarine Correia Paes Barreto ${ }^{2}$, Duana Gabrielle de

Lemos Costa $^{3}$, Fábia Monique da Silva ${ }^{4}$, Maria Isabelle Barbosa da Silva Brito ${ }^{5}$

${ }^{1}$ Faculdade de Enfermagem Nossa Senhora das Graças, Universidade de Pernambuco, Recife, PE, Brasil. Grupo de pesquisa CNPq: Neonatos, Crianças e Adolescentes CISAM/UPE

${ }^{2}$ Hospital das Clínicas de Pernambuco, Recife, PE, Brasil.

${ }^{3}$ Instituto de Medicina Integral Professor Fernando Figueira, Recife, PE, Brasil.

${ }^{4}$ Centro Universitário Tabosa de Almeida, Caruaru, PE, Brasil.

${ }^{5}$ Instituto Aggeu Magalhães - FIOCRUZ/PE, Recife, PE, Brasil.

*Correspondência: Faculdade de Enfermagem Nossa Senhora das Graças, Universidade de Pernambuco, Campus Santo Amaro, Rua Arnóbio Marques, 310 Santo Amaro, Recife, Pernambuco, Brasil. CEP: 50100-130. e-mail: sandra.low@upe.br

Artigo recebido em 04/01/2019 aprovado em 18/06/2019 publicado em 02/10/2019.

\section{RESUMO}

Dentre os espaços de cuidados à criança, a creche tem sido motivo de estudo no que diz respeito às doenças e agravos à saúde infantil, por compor um ambiente coletivo, aumentando a circulação de agentes patogênicos. O objetivo deste estudo foi identificar doenças e agravos prevalentes em crianças que frequentam a creche, pelo olhar dos funcionários. Trata-se de um estudo descritivo e quantitativo. 47 profissionais participaram do estudo, a faixa etária prevalente estava entre 15-30 anos (66\%). Quanto ao cargo ocupado, 54,7\% estavam na instituição a menos de um ano, e 19,1\% eram estagiários. Para 93,3\% dos entrevistados, as gripes e resfriados são as principais doenças prevalentes e 27,7 \% referem quedas como mais frequentes agravos nas crianças da creche. Além disso, 76,6\% identificaram que são realizadas ações de prevenção e promoção da saúde, e 34\% afirmaram que o público alvo das ações são os funcionários da creche. $68,1 \%$ relataram que o público alvo deve ser todos os envolvidos no desenvolvimento da criança. 40,4\% assinalaram que a frequência das ações de prevenção deveria ser duas ou mais vezes no mês. Com isso, destaca-se a necessidade de realização de ações de promoção da saúde que envolvam os pais, crianças e os funcionários da creche a fim de garantir a integralidade do cuidado.

Palavras-chave: Creche; Saúde da Criança; Atenção Integrada às Doenças Prevalentes na Infância.

\section{ABSTRACT}

Among childcare spaces, day care centers have been the subject of study in relation to child health problems, since they constitute a collective environment, increasing the circulation of pathogens. The objective of this study was to identify diseases and disorders prevalent in children who attend day care, due to the employees' gaze. This is a descriptive and quantitative study. 47 professionals integrated the study, the prevalent age group was between 1530 years (66\%). As for the position held, $54.7 \%$ were in the institution less than a year, and $19.1 \%$ were trainees. For 93.3\% of the respondents, the flu and colds are the main diseases / diseases prevalent in daycare children. In addition, $76.6 \%$ identified that prevention and health promotion actions are carried out, and $34 \%$ stated that the target audience for the actions are day care staff. $68.1 \%$ reported that the target audience should be all involved in the development of the child. 40.4\% indicated that the frequency of preventive actions should be two or more times in the month. This highlights the need to carry out health promotion actions involving parents, children and day care staff in order to guarantee the integrality of care.

Keywords: Day-care; Child Health; Integrated Management of Childhood Illness. 


\section{RESUMEN}

Entre los espacios de atención al niño, la guardería ha sido motivo de estudio en lo que se refiere a los agravios a la salud infantil, por componer un ambiente colectivo, aumentando la circulación de agentes patógenos. El objetivo de este estudio fue identificar enfermedades/agravios prevalentes en niños que frecuentan la guardería, por la mirada de los funcionarios. Se trata de un estudio descriptivo y cuantitativo. 47 profesionales integraron el estudio, grupo de edad prevalente estaba entre 15-30 años (66\%). 54,7\% estaban en la institución a menos de un año, 19,1\% eran pasantes. 93,3\% relató las gripes y resfriados son las principales enfermedades/agravios prevalentes en los niños. 76,6\% identificó que se realizan acciones de prevención y promoción de la salud, $34 \%$ afirmó que el público de las acciones son los funcionarios de la guardería. $68,1 \%$ relató que el público debe ser todos los involucrados en el desarrollo del niño. 40,4\% señaló que la frecuencia de las acciones de prevención debería ser dos o más veces en el mes. Se destaca la necesidad de realizar acciones de promoción de la salud que involucren a los padres, niños y los funcionarios de la guardería a fin de garantizar la integralidad del_cuidado.

Descriptores: Creches; Salud del Niño; Atención Integrada a las Enfermedades Prevalentes de la Infancia.

\section{INTRODUÇÃO}

O Estatuto da Criança e do Adolescente, amparado pela Constituição Brasileira de 1988 e pela Lei de Diretrizes e Bases da Educação $n^{\circ}$ 9.394, de 20 de dezembro de 1996, traz o direito da educação infantil como dever do Estado, atuando por meio do atendimento em creches e pré-escolas às crianças de faixa etária de 0- 6 anos (MOTTA et al., 2012), sendo este um espaço de crescimento, desenvolvimento, educação e socialização.

A história da creche está intimamente ligada às modificações do papel da mulher na sociedade, como integrante do mercado de trabalho. As primeiras creches no Brasil surgiram do século XIX, e desde então a finalidade da creche é compor um ambiente para cuidar e proteger as crianças (SEABRA e MOURA, 2005).

Durante a infância a preocupação com o desenvolvimento deve ser prioritário, visto que o desenvolvimento infantil está relacionado a mudanças nas estruturas físicas, neurológicas, cognitivas e comportamentais. Atualmente, o ambiente da creche é concebido como um espaço de educação infantil, no qual contribui com o desenvolvimento da criança desde os primeiros meses de vida, incentivando a socialização das crianças e aprimorando as relações interpessoais que são estimuladas a partir do convívio com os outros pares (MOTTA et al., 2012; SANTOS et al., 2010).

O interesse pela atenção à saúde da criança vem crescendo nos últimos anos por meio de programas que promovem o cuidado de forma integral, priorizando os grupos de risco. Esta mudança no perfil da estratégia de atenção à saúde da criança se deu na década de 90, através da criação da estratégia de Atenção Integrada às Doenças Prevalentes na Infância (AIDPI). Dentre os espaços de cuidado à criança, a creche tem sido motivo de estudo no que diz respeito aos agravos da saúde infantil, por compor um ambiente coletivo, aumentando a circulação de agentes patogênicos (SANTOS et al., 2010; SILVA et al., 2011).

Considerando as ocorrências e agravos a saúde dessas crianças, os acidentes na infância são encontrados com frequência nestes espaços, devido ao grande fluxo num mesmo espaço físico. Neste sentido, os profissionais de saúde demandam mais atenção quando estas crianças vivem em comunidades de baixa renda, onde o acesso aos equipamentos sociais é mais difícil e restrito (SILVA et al., 2011).

O ambiente da creche é favorável ao aumento das doenças e agravos à saúde da criança, deste modo se faz necessário a presença de um profissional de 
saúde neste ambiente, para reconhecer quais os fatores de riscos que podem impactar na saúde da criança de forma positiva e/ou negativa (SILVA et al., 2011). O enfermeiro é o profissional da saúde que desde a sua graduação é ensinado a trabalhar como educador em saúde. Assim, a creche representa mais uma área de atuação, onde este profissional de saúde poderá realizar ações de promoção e proteção a saúde junto às crianças, seus pais/familiares e funcionários da creche (MARANHÃO, 2017).

Contudo, a presente pesquisa teve como objetivo, identificar as doenças e os agravos prevalentes em crianças de creche, pelo olhar dos funcionários, a fim de promover o conhecimento para posterior construção de medidas de prevenção para saúde da criança que frequenta a creche, pois o desenvolvimento adequado da criança está diretamente ligado a diversos fatores, como os de adaptação ambiental.

\section{MATERIAIS E MÉTODOS}

Trata-se de um estudo descritivo com abordagem quantitativa (MEDRONHO, 2009), realizado no período de fevereiro a agosto de 2015, cuja população alvo foram funcionários da Creche Municipal Professor Francisco do Amaral Lopes, localizada na Avenida Governador Agamenon Magalhães, no bairro de Santo Amaro, Distrito Sanitário I, do município do Recife/PE. Foi considerado elegível para o estudo, funcionários da creche, sem distinção de idade, sexo ou raça, que concordaram em participar da pesquisa e assinaram o Termo de Consentimento Livre e Esclarecido (TCLE), para os menores de 18 anos, obteve-se a assinatura de seus responsáveis e posteriormente responderam aos questionários. A amostra foi composta por um total de 47 funcionários.

A operacionalização da coleta de dados aconteceu em apenas uma etapa. Após os funcionários serem devidamente esclarecidos sobre a pesquisa, puderam assinar o Termo de Consentimento Livre e Esclarecido (TCLE) e em seguida, foi aplicado um questionário estruturado, elaborado pelas autoras, com questões objetivas, sendo este dividido em três secções. A primeira parte objetivou uma caracterização sócio demográfica dos integrantes; a segunda parte do questionário buscou os conhecimentos sobre as doenças e agravos prevalentes nas crianças da creche e por fim, a terceira parte trouxe questões sobre a realização de ações de prevenção e promoção à saúde das crianças da creche.

A análise e tabulação dos dados foram realizadas inicialmente em planilha pelo Software Microsoft Office Excel 2016. Posteriormente, os dados foram devidamente inseridos, tabulados e processados utilizando-se Software Statistical Package for Social Science (SPSS), versão 2.0.

O projeto foi realizado respeitando os princípios da Bioética, registrados na Resolução No 466, de 12 de dezembro de 2012, do Conselho Nacional de Saúde, sobre pesquisa envolvendo seres humanos. Sendo apresentado e aprovado pelo Comitê de Ética em Pesquisa do Centro Integrado de Saúde Amaury Medeiros (CISAM), mediante o parecer $n^{\circ}: 911.978$ e Certificado de Apresentação para Apreciação Ética (CAAE) $n^{\circ}: 34958214.7 .0000 .5191$.

\section{RESULTADOS E DISCUSSÃO}

A Creche Municipal Professor Francisco do Amaral Lopes é formada por 100 crianças matriculadas, os quais são distribuídos entre os gêneros masculinos e femininos, possui quatro salas de aula, um berçário, uma copa, um expurgo, uma secretaria, um refeitório, e área de lazer para as crianças. A equipe de profissionais que integra o quadro de funcionários internos e externos é composta por 47 sujeitos. Ao analisar os dados coletados dentre os 47 funcionários do quadro, identificou-se que o 
gênero feminino foi o mais prevalente, com 95,7\% $(\mathrm{N}=45)$ e o gênero masculino com $4,3 \%(\mathrm{~N}=2)$. A faixa etária predominante foi a situada no intervalo entre 15 e 30 anos, totalizando $66 \%(\mathrm{~N}=31)$ da amostra. Com relação ao nível de escolaridade, houve predomínio do ensino médio completo representando $27,7 \%(\mathrm{~N}=13)$ do total, conforme ilustrado na Tabela 1.

Tabela 1. Perfil Sócio demográfico dos profissionais da creche no ano 2015. Recife - PE, 2015.

\begin{tabular}{|c|c|c|}
\hline Variáveis & $\mathbf{N}=47$ & $\%$ \\
\hline \multicolumn{3}{|l|}{ Sexo } \\
\hline Feminino & 45 & 95,7 \\
\hline Masculino & 2 & 4,3 \\
\hline \multicolumn{3}{|l|}{ Faixa Etária } \\
\hline $15-30$ & 31 & 66 \\
\hline $31-40$ & 3 & 6,4 \\
\hline $41-50$ & 13 & 27,7 \\
\hline \multicolumn{3}{|l|}{ Escolaridade } \\
\hline Ensino Fundamental Incompleto & 4 & 8,5 \\
\hline Ensino Fundamental Completo & 10 & 21,3 \\
\hline Ensino Médio Incompleto & 3 & 6,4 \\
\hline Ensino Médio Completo & 13 & 27,7 \\
\hline Ensino Superior Incompleto & 5 & 10,6 \\
\hline Ensino Superior Completo & 7 & 14,9 \\
\hline Pós Gradução & 5 & 10,6 \\
\hline \multicolumn{3}{|l|}{ Profissão } \\
\hline Administrativo & 4 & 8,5 \\
\hline Coordenação & 2 & 4,3 \\
\hline Cuidador (a) & 8 & 17 \\
\hline Diretora & 1 & 2,1 \\
\hline Estagiário (a) & 9 & 19,1 \\
\hline Merendeira & 3 & 6,4 \\
\hline Porteiro (a) & 1 & 2,1 \\
\hline Professora & 5 & 10,6 \\
\hline Segurança & 1 & 2,1 \\
\hline Serviços Gerais & 5 & 10,6 \\
\hline Não Respondeu & 8 & 17 \\
\hline \multicolumn{3}{|l|}{ Tempo de Trabalho na Instituição } \\
\hline$<1$ ano & 27 & 57,4 \\
\hline 1 a 3 anos & 9 & 19,1 \\
\hline 3 a 5 anos & 1 & 2,1 \\
\hline$\geq 5$ anos & 10 & 21,3 \\
\hline
\end{tabular}

Fonte: Banco de dados deste estudo.

Constatou-se que os estagiários (as) foram os mais prevalentes com relação à composição da equipe, apresentando 19,1\% (N=9). Além disso, a maior parte dos integrantes da equipe estava na instituição a menos de um ano, o que representou $57,4 \%(\mathrm{~N}=27)$ da amostra, como se pode observar ainda na Tabela 1. 
É crescente a utilização da creche pelas famílias brasileiras. Diversos fatores socioeconômicos vêm contribuindo para que isto ocorra, entretanto, a creche torna-se um ambiente de risco para a disseminação de doenças infecto contagiosas e parasitárias, bem como para o aumento do risco de acidentes na infância devido ao fluxo existente. Dessa forma, faz-se necessário, que haja cada vez mais estudos sobre este ambiente, a fim de proporcionar um serviço de qualidade que preserve e promova saúde das crianças (OLIVEIRA et al., 2013).

Segundo o estudo (PEDRAZA et al., 2014), a transmissão de doenças infecciosas e parasitárias ocorre pelo fato do ambiente da creche favorecer a disseminação dos vetores, visto que abriga uma população com perfil característico e sob risco específico para a transmissão: crianças aglomeradas recebendo cuidados de forma coletiva (PEDRAZA et al., 2014). Diferenciando um pouco da presente pesquisa, visto que, quando foram questionados a respeito das doenças prevalentes nas crianças da creche, $93,3 \% \quad(\mathrm{~N}=44) \quad$ dos entrevistados, que poderiam responder a mais de uma opção, apontaram a gripe e resfriado (infecções comuns), em seguida, $70,2 \%(\mathrm{~N}=33)$ indicaram a diarreia e 40,4\% ( $=19)$ assinalaram a disenteria, como se pode confirmar na tabela 2.

As chances de uma criança desenvolver otite média, aumentam de duas a três vezes mais quando ela frequenta a creche, corroborando com esse estudo, pois $8,5 \%$ dos funcionários referiram a otite como uma doença prevalente (PEDRAZA et al., 2014).

A quarta doenças mais citada como prevalente foi a conjuntivite representando $31,9 \% \quad(\mathrm{~N}=15)$, doença caracterizada por uma inflamação na conjuntiva ocular, causada por etiologia infecciosa (viral e bacteriana) e não infecciosa (alérgica e não alérgica) (KANSKI, 2004). A conjuntivite bacteriana é a mais frequente em crianças, esta doença tem um alto poder de contágio, por isso é recomendado que crianças com conjuntivite não frequentem a creche até que sejam examinadas por um médico e o mesmo libere o seu retorno à creche após o tratamento adequado (SOARES e NETTO, 2010).

Tabela 2. Doenças e Agravos Prevalentes nas Crianças da Creche, sob o olhar dos Funcionários. Recife - PE, 2015. *

\begin{tabular}{ccc}
\hline Variáveis & $\mathbf{N = 4 7}$ & $\mathbf{\%}$ \\
\hline Gripe e Resfriado & 44 & 93,6 \\
Diarreia & 33 & 70,2 \\
Quedas & 13 & 27,7 \\
Escabiose & 10 & 21,3 \\
Disenteria & 19 & 40,4 \\
Otite & 4 & 8,5 \\
Pediculose & 10 & 21,3 \\
Conjuntivite & 15 & 31,9 \\
Outros & 7 & 14,9 \\
\hline
\end{tabular}

* Os entrevistados poderiam responder a mais de uma alternativa.

Fonte: Banco de dados deste estudo.

Já a escabiose, causada pelo ectoparasito denominado de ácaro da espécie Sarcoptes scabiei, e a pediculose causada pelo parasita Pediculus Humanus, foram apontadas por $21,3 \%(\mathrm{~N}=10)$ dos participantes. Estas doenças parasitárias têm alta contagiosidade, por isso a importância dos funcionários ficarem atentos aos seus sinais, para que o controle e o combate ocorram o mais precocemente possível, impedindo a disseminação na creche.

Dentre os acidentes prevalentes na infância, a pesquisa (MARTINS e ANDRADE, 2005), apontou a queda como o mais recorrente, sendo a principal causa de atendimento hospitalar e de internação entre crianças. As lesões vão de simples escoriações até lesões mais graves. De acordo com a Tabela 2, as quedas foram referidas por $27,7 \% \quad(\mathrm{~N}=13)$ dos entrevistados. Dessa forma, pode-se utilizar a educação em saúde para prevenir os vários agravos 
que as crianças estão expostas, dentre eles as quedas (MARTINS e ANDRADE, 2005).

Todos os agravos referenciados pelos entrevistados, podem ser facilmente evitados dentro do ambiente da creche. Portanto, evidencia-se a importância do setor saúde neste ambiente, sendo o enfermeiro, um exemplo de profissional que poderá executar ações que promovam o cuidado, juntamente com os funcionários da creche, crianças, pais e familiares. Além disso, os funcionários da creche podem ser os primeiros a identificar os agravos de saúde nas crianças, e assim, o enfermeiro pode ajudá- los nesse processo, possibilitando uma intervenção correta e precisa que contribuirá com a manutenção da saúde das crianças (MARANHÃO, 2017; RODRIGUES et al., 2014).

Considerando a realização de ações de prevenção e promoção da saúde, voltadas para as crianças que frequentam a creche, pode-se visualizar através da Tabela 3 , que 76,6\% (N=36) dos funcionários entrevistados responderam que são realizadas ações de prevenção e promoção da saúde, entretanto, 23,4\% (N=11) dos funcionários negaram que são realizadas tais ações.

Tabela 3. Realização de Ações de Prevenção e Promoção da Saúde das crianças que frequentam a creche. Recife PE, 2015.

\begin{tabular}{|c|c|c|}
\hline Variáveis & $\mathrm{N}=\mathbf{4 7}$ & $\%$ \\
\hline \multicolumn{3}{|c|}{ São realizadas ações de Prevenção e Promoção para essas doenças e agravos } \\
\hline Sim & 36 & 76,6 \\
\hline Não & 11 & 23,4 \\
\hline \multicolumn{3}{|c|}{ Público alvo das palestras Realizadas na creche* } \\
\hline Funcionários & 16 & 34 \\
\hline Crianças & 3 & 6,4 \\
\hline Pais & 7 & 14,9 \\
\hline Todos & 32 & 68,1 \\
\hline \multicolumn{3}{|c|}{ Com que frequência as ações são desenvolvidas } \\
\hline \multirow[t]{2}{*}{ Uma vez por semana } & 10 & 21,3 \\
\hline & 11 & 23,4 \\
\hline \multicolumn{3}{|l|}{ Uma vez no mês } \\
\hline Duas vezes ou mais no mês & 10 & 21,3 \\
\hline Semestralmente & 5 & 10,6 \\
\hline Não respondeu & 11 & 23,4 \\
\hline
\end{tabular}

* Os entrevistados poderiam responder a mais de uma alternativa.

Fonte: Banco de dados deste estudo.

Além disso, 68,1\% (N=32) consideraram que o público alvo para essas ações de prevenção e promoção da saúde, foram os próprios funcionários, as crianças e os pais (tabela 3). Dessa forma, é importante avaliar a creche como ambiente de fonte de transmissão de doenças infecciosas, não só para as crianças, mas também para os funcionários, pais, como também toda a comunidade. Para que as doenças e agravos sejam minimizados, se faz necessário planejamento de ações de prevenção e promoção a saúde e manutenção do ambiente da creche de modo que garanta o desenvolvimento saudável da criança. 
Alguns fatores estruturais da creche devem ser levados em consideração para adequada prevenção, como ambientes que permitam a circulação de ar e a entrada de raios de sol, as paredes, o piso e todos os materiais de lazer devem ser de fácil higienização (SARUBBI JÚNIOR, et al., 2014).

Quanto à frequência da realização dessas ações, 23,4\% (N=11) dos entrevistados afirmaram que são desenvolvidas uma vez no mês, ressaltando que o mesmo percentual não respondeu esta alternativa. Ressalta-se a atenção aos participantes da pesquisa serem estagiários de alta rotatividade, justificando que estes funcionários não terem sido alcançados pelas ações e/ou não identificam que estas ações são realizadas. 21,3\% ( $\mathrm{N}=10)$ afirmaram que toda semana são desenvolvidas ações de prevenção, e ainda, 10,6\% $(\mathrm{N}=5)$ dos funcionários apontaram que as ações são desenvolvidas semestralmente, como ilustra a tabela 3 .

A creche bem estruturada deve ser capaz de identificar precocemente algumas doenças infecciosas, já que a literatura conhece e refere o fato de que as crianças que a frequentam regularmente, estão mais expostas aos riscos (SARUBBI JÚNIOR, et al., 2014). No entanto, o processo de identificação de doenças e agravos ainda não está estabelecido por todos os serviços.

As práticas preventivas em saúde podem ser realizadas em qualquer espaço social, com o objetivo de promover a saúde, buscando melhoria da qualidade de vida. Como as crianças não têm autonomia satisfatória para cuidarem da própria saúde, elas têm o direito de receber cuidados e apoio em sua formação (FARIA e WICHR, 2014).

Apesar de não portarem um olhar ampliado sobre as especificidades da promoção de saúde pediátrica, a maioria dos integrantes deste estudo é consciente da necessidade de desenvolver ações preventivas na creche. A partir da Tabela 4, visualizase que $46,8 \%(\mathrm{~N}=22)$ da amostra apontaram palestras como forma de prevenir doenças e agravos infantis, assim como $46,8 \%(\mathrm{~N}=22)$ indicaram as reuniões como mais uma alternativa para esta prática e $27,7 \%$ $(\mathrm{N}=13)$ sugeriram a visita domiciliar como mais um meio de prevenção à saúde.

Observa-se que palestras, reuniões e visitas domiciliares são medidas simples e eficazes de prevenção e detecção precoce das doenças e agravos prevalentes na infância. Estas ações fornecem conhecimentos para os que cuidam nos diversos ambientes onde as crianças permanecem no seu cotidiano (MARANHÃO, 2010; MOTTA et al., 2012).

Ainda de acordo com a Tabela 4, pode-se evidenciar que 40,4\% ( $\mathrm{N}=19)$ dos funcionários assinalaram que a frequência das ações deveria ser duas ou mais vezes no mês. Este resultado representa que a maioria dos participantes almeja por ações preventivas mais frequentes. Porém, $4,3 \%(\mathrm{~N}=2)$ dos entrevistados apontaram para realização de ações semestrais, o que indica que não estão dotados de conhecimentos suficientes sobre a importância da prática frequente de prevenção.

Além da formação e instrução pedagógica dos educadores/cuidadores infantis, se faz necessário a inclusão de conteúdos que abordem a promoção a saúde, reduzindo o risco de adoecimento, acidentes e a disseminação de doenças infecciosas no ambiente, com medidas e noções básicas de higiene, acidentes e alimentação tendo em vista que o risco da disseminação de doenças e agravos é maior em crianças que frequentam a creche em relação àquelas que são cuidados dentro do ambiente familiar (FARIA e WICHR, 2014). A exposição 
as doenças e agravos na creche está relacionada com estar convivendo em aglomerados porque facilita a disseminação de agentes infecciosos nesta população e devido ao número de crianças expostas a estes agentes (SARUBBI JÚNIOR, et al., 2014), o que enfatiza a necessidade de ações serem desenvolvidas com toda a família da criança, como é identificado no presente estudo, onde $68,1 \%(\mathrm{~N}=32)$ dos entrevistados relataram que o público alvo deve ser todos aqueles que estão envolvidos no desenvolvimento da criança (funcionários da creche e os pais), como também a própria criança, para promover o auto cuidado e por considerar que elas são avaliadas como formadoras de opinião no meio familiar, sendo capazes de moldar e reformular conceitos e tradições, levando o conteúdo aprendido na creche para a rotina do lar. Isso reflete que a maioria dos funcionários é conhecedora de que os saberes e práticas que integrem cuidar e educar na atenção infantil é um grande desafio, que terá êxito se houver um trabalho conjunto entre creche e família.

Tabela 4. Desenvolvimento de ações de Promoção e Prevenção a Saúde das Crianças da Creche que na opinião dos Funcionários podem ser realizadas. Recife - PE, 2015.

\begin{tabular}{lll}
\hline VARIÁVEIS & $\mathrm{N}=47$ & $\%$ \\
\hline
\end{tabular}

De que forma ações de prevenção ás doenças e agravos podem ser desenvolvidas*

Palestras

Reuniões

Visita Domiciliar

Com que frequência essas ações podem ser desenvolvidas

Semanalmente

Mensalmente

Duas ou mais vezes no Mês

Semestralmente

Qual deve ser o público alvo destas ações

Funcionários da Creche

Crianças da Creche

Pais das Crianças que frequentam a Creche

Todos

Os entrevistados poderiam responder a mais de uma alternativa.

Fonte: Banco de dados deste estudo.

Nesse contexto, o profissional enfermeiro pode atuar em parceria com os professores e gestores de creches, ampliando seu foco para além das doenças e agravos a saúde, de modo que poderá exercer influência sobre o estilo de vida das crianças e modificar a prática do cuidado na creche e no ambiente doméstico (MARANHÃO, 2017).

A disseminação de doenças infecciosas no ambiente da creche está relacionada com os maus hábitos de higiene, inerentes a faixa etária infantil, 
como levar a mão e objetos contaminados à boca, imaturidade do sistema imunológico da criança, além das ações ineficientes e inadequadas dos profissionais no manuseio com mãos sujas das crianças como troca de fraldas, preparo de alimentos, higiene do ambiente e brinquedos, além do número de crianças que ocupam o mesmo espaço físico (PEDRAZA et al., 2014). Desta forma é importante considerar algumas medidas de controle para infecção, corroborando com os 61,7 \% $(\mathrm{N}=29)$ dos profissionais que apontaram como medidas consideradas eficazes para o controle de infecções na creche a redução da frequência de crianças doentes na creche, a atualização do cartão vacinal, a lavagem das mãos e a desinfecção das paredes e objetos do ambiente (Tabela 5).

Tabela 5. Medidas consideradas eficazes para o controle de infecções na creche, segundo os funcionários. Recife - PE, 2015. *

\begin{tabular}{lcc}
\hline VARIÁVEIS & N=47 & \% \\
\hline Todas as medidas são eficazes & 29 & 61,7 \\
Impedir a Frequência de Crianças Doentes na Creche & 11 & 23,4 \\
Vacinação das Crianças & 9 & 19,1 \\
Lavagem das Mãos & 8 & 6,4 \\
Desinfectar as Paredes e Objetos da Creche & 3 & 6 \\
\hline
\end{tabular}

*Os entrevistados poderiam responder a mais de uma alternativa.

Fonte: Banco de dados deste estudo.

A vacinação é um método integrado e, rotineiro dos serviços de saúde na atenção primária, e possui grande impacto porque possibilita o enfretamento de doenças a nível individual, ao mesmo tempo que evita a transmissão das mesmas no meio coletivo (CAVALCANTI e NASCIMENTO, 2015). Estudo realizado na Angola em 2010 (OLIVEIRA et al., 2014), aponta que apesar da comprovação e da divulgação dos benefícios da imunização, existem muitos fatores associados na manutenção da cobertura vacinal das crianças, pois algumas barreiras interferem na ampla cobertura vacinal, as quais estão associadas a aspectos socioculturais, tais como nível de educação da população, escolaridade dos pais, renda familiar e idade da criança.

Além disso, A lavagem das mãos é uma medida de prevenção de doenças, a qual se for exercida de forma correta poderá diminuir custos e controlar de afecções (COSTA, 2011). De acordo com Lesmes e colaboradores (2017), o número de crianças que tem o hábito de lavagem das mãos dentro da creche é reduzido. Este habito pode ser encorajado por adultos, uma vez que, estes possuam o habito de lavagem das mãos de maneira rotineira. Esse estudo evidencia também que os cuidadores das crianças conhecem os 10 passos de higienização das mãos, porém não os realizam de forma oportuna.

Nesse sentido, um dos desafios do Enfermeiro dentro da creche seria promover suporte técnico necessário aos Cuidadores, Professores e Diretor da creche, para o desenvolvimento de práticas que contribuam com a manutenção da saúde da criança, como ensinar a realização da técnica adequada de 
lavagem das mãos, incentivar e orientar a limpeza e higienização do ambiente, brinquedos e utensílios da creche, bem como promover ações de vigilância da situação vacinal da criança e orientar e articular junto ao serviço de saúde a atualização da situação vacinal das crianças (MARANHÃO, 2017).

\section{CONCLUSÃO}

A creche tem responsabilidades que vão além da educação infantil. Este ambiente também envolve a prestação de cuidados básicos de saúde, incluindo a segurança física e emocional, os cuidados relativos à higiene, alimentação e afeto. Deste modo, este estudo possibilitou entender que as doenças e agravos que mais acometem crianças que frequentam uma creche municipal na cidade do Recife são gripes e resfriados, contribuindo para a elaboração estratégias que minimize e/ou erradique essas doenças neste ambiente, visto que são preveníveis por bons hábitos de saúde.

Pode-se afirmar que é de suma importância a realização de ações de promoção da saúde que envolvam os pais, crianças e os funcionários da creche. Os achados do estudo apontam que ações precisam ser voltadas para orientações referentes aos benefícios da situação vacinal atualizada da criança, aumento da imunidade infantil por alimentos saudáveis, higienização e hidratação nasal individual, importância da lavagem das mãos e higienização do ambiente e brinquedos da creche além de esclarecimento de dúvidas sobre por que motivos a criança deverá ser afasta da creche.
É importante que incansavelmente se busque parcerias com profissionais de saúde em creches além de demarca-la com indicadores de adoecimento que possibilitem no processo dos educadores o reconhecimento dos perigos escondidos neste ambiente. Desta forma as intervenções preventivas poderão garantir a integralidade do cuidado neste ambiente.

\section{AGRADECIMENTOS}

Agradecemos a todos os funcionários da Creche Municipal Professor Francisco do Amaral Lopes, pela participação no estudo e a Universidade de Pernambuco (UPE) pelo incentivo e apoio para desenvolvimento da pesquisa.

Todos os autores declararam não haver qualquer potencial conflito de interesses referentes a este artigo.

\section{REFERÊNCIAS}

CAVALCANTI, M. A. F; NASCIMENTO, E. G. C. Aspectos Intervenientes da criança, da família e dos serviços de saúde na imunização infantil. Rev Soc Bras Enferm Ped. v. 15, n.1, p. 31-37, 2015.

COSTA, F. B. Higiene das mãos e na alimentação infantil: a atuação do enfermeiro na atenção básica. 19f. Trabalho de Conclusão de Curso (Especialização em Atenção Básica em Saúde da Família). Universidade Federal de Minas Gerais. Belo Horizonte, 2011.

FARIA, M. L.; WICHR, P. Creche, Criança e Saúde. Rev. Mineira de Enfermagem. v. 19, n.1, p.142-146, 2014.

KANSKI, J. J. Oftalmologia clínica. Rio de Janeiro: Elsevier, 2004.

LESMES, V.I.S.; RAMÍREZ, O.J.G.; PARRADO, Y.M.; RODRÍGUEZ, P.H.; GOMEZ, A.P. Caracterización de hábitos de 
higiene y ambientes en lugares de atención integral a población infantil. Revista da escola de enfermagem da USP. v.51, n.1, p. 1-7, 2017.

MARANHÃO, D.G. Atuação do enfermeiro em creches. In: GAIVA, M.A.M.; TOSO B.R.G.O; MANDETTA, M.A. (eds), PROENF Programa de Atualização em Enfermagem: Saúde da Criança e do Adolescente: Ciclo 11. Porto Alegre, Artmed Panamericana, p. 117-153; 2017.

MARANHÃO, D.G. Saúde e bem-estar das crianças: uma meta para educadores infantis em parceria com familiares e profissionais de saúde. São Paulo, SP. Dissertação de mestrado. Universidade Federal de São Paulo UNIFESP; 2010.

MARTINS, C.B.G.; ANDRADE, S.M. Epidemiologia dos acidentes e violências entre menores de 15 anos em município da região sul do Brasil. Rev. Latino-Americana de Enfermagem. v.13, n.4, p.530-537, 2005.

MEDRONHO, R.A., et al. Epidemiologia. 2 ed., Rio de Janeiro, Atheneu; 2009.

MOTTA, J. A; SILVA, P.O.; MARTA, P.O.; ARAÚJO, B.B.M.; FRANCISCO, M.T.R.; SEABRA JÚNIOR, H.C. . O cuidado à criança na creche: integração entre saúde e educação. Rev. Enfermagem UERJ, v.2, n.20, p.771776, 2012.

OLIVEIRA, J.S.; LIRA, P.I.C; CARVALHO, A.G.C.; BARROS, M.F.A.; LIMA, M.C. Fatores associados ao estado nutricional em crianças de creches públicas do município de Recife, PE, Brasil. Rev. Brasileira de Epidemiologia. v.16, n.2, p.502-512, 2013.

OLIVEIRA, M.F.S.; MARTINEZ E.Z.; ROCHA, J.S,Y. Factors associated with vaccination coverage in children $<5$ years in Angola. Revista de Saúde Pública. v.48, n. 6, p. 906-915, 2014.

PEDRAZA, D.F.; QUEIROZ, D.; SALES, M.C. Doenças infecciosas em crianças préescolares brasileiras assistidas em creches. Rev. Ciência \& Saúde Coletiva. v.19, n.2, p.511528, 2014.
RODRIGUES, B.C.; D'ARTIBALE, E.F.; BARBIERI, M.C.; BERCINI, L.O.; HIGARASHI, I.H. Intersecções do cuidado à saúde nos centros de educação infantil: percepção das mães. Revista de Enfermagem UERJ. v.22, n.1, p.71-76, 2014.

SANTOS, M.E.A.; QUINTÃO, N.T.; ALMEIDA, R.X. Avaliação dos marcos do desenvolvimento infantil segundo a estratégia da atenção integrada às doenças prevalentes na infância. Escola Anna Nery. v. 4, n.3, p.1-9, 2010.

SARUBBI JUNIOR, V.; MUYLAERT, C.J.; GALLO, S.M.; GALLO, P.R. In the context of a daycare center: nursing and their representations of child care as an educational act. Revista da Escola de Enfermagem da USP.v.48, n.2, p.46-52, 2014.

SEABRA, K. C; MOURA, M.L.S. Alimentação no ambiente de creche como contexto de interação nos primeiros dois anos de um bebê. Psicologia em Estudo. v.10, n.1, p.77-86, 2005.

SILVA, D.B.; TESTA, G.M.; NASCIMENTO, M.E.B. In. III Conclave dos Acadêmicos de Enfermagem da Universidade Positivo, Curitiba, Anais. v. 3, p.100-103, 2011.

SOARES, A.S.; NETTO, A.A.. Análise da prevalência de conjuntivite no atendimento emergencial do serviço de oftalmologia do Hospital Universitário da Universidade Federal de Santa Catarina nos anos de 2004 a 2008. Arquivos Catarinenses de Medicina. v.39, n.2, p.50-55, 2010. 